\title{
Sustainability Jam Sessions for vision creation and problem solving
}

\author{
Anders Carlsson, Olof Hjelm, Leenard Baas, Mats Eklund, Joakim Krook, \\ Mattias Lindahl and Tomohiko Sakao
}

\section{Linköping University Post Print}

\section{Tweet}

N.B.: When citing this work, cite the original article.

Original Publication:

Anders Carlsson, Olof Hjelm, Leenard Baas, Mats Eklund, Joakim Krook, Mattias Lindahl and Tomohiko Sakao, Sustainability Jam Sessions for vision creation and problem solving, 2014, Journal of Cleaner Production.

http://dx.doi.org/10.1016/j.jclepro.2014.10.041

Copyright: Elsevier http://www.elsevier.com/

Postprint available at: Linköping University Electronic Press http://urn.kb.se/resolve?urn=urn:nbn:se:liu:diva-112725 


\title{
Sustainability Jam Sessions for vision creation and problem solving
}

Anders Carlsson, Olof Hjelm, Leo Baas, Mats Eklund, Joakim Krook, Mattias Lindahl and Tomohiko Sakao

Environmental Technology and Management, Department of Management and Engineering, Linköping University, SE-581 83 Linköping, Sweden

Corresponding author: Anders Carlsson, E-mail address: anders.carlsson@liu.se , Tel +46 13281801

\begin{abstract}
This article presents a concept for creating arenas where expertise from certain branches of industry can interact with sustainability professionals and researchers to address and solve sustainability challenges. The concept Sustainability Jam Session (SJS) builds upon the idea of conducting creative meetings between professionals in "jam sessions," similar to those associated primarily with music and improvisation. Approaches such as these have been used in the IT sector over the past decades, but this is the first attempt to apply it in the area of sustainability. SJS's were tested at the 2012 Greening of Industry Network Conference (GIN2012) and here we report our experiences from arranging six SJS's at the conference.
\end{abstract}

A typical process of an SJS includes a preparatory phase, the actual jam, and documentation and follow up. The preparatory phase mainly involves identifying hosts and topics to be addressed at the SJS, followed by attracting participants. The jam is started by an introduction of the topics, a technical visit (if appropriate), and a problem-solving workshop, ending with a wrap-up reporting. Thorough documentation is necessary for following up the results of the SJS and preparing for implementation of the identified solutions.

We conclude that skill, structure, setting, and surrender of control, as well as finding "red and hot" topics for the jams are the key factors for successful SJS's.

Based on our experiences from GIN2012, we recommend other research conferences in the sustainability field use SJS's if the intention is to boost the interaction between the conference and the host region or non-academic organizations in general. We also suggest that a similar approach can be used in regional development for creating an infrastructure for learning and transformation towards sustainability and initiatives for open innovation. 


\section{Introduction}

Solutions to major environmental challenges such as depletion of natural resources, climate change, and loss of biodiversity call for an interdisciplinary approach. In addition, despite the tremendous growth over the last decade of academic studies of measures and activities for solving environmental problems, vast practical knowledge and experience, and increased general awareness among citizens, many challenges still are unresolved (see Rockström et al., 2009 for an overview). Many of the improvements achieved so far are of an incremental nature or limited to implementation only at a local or regional level.

One explanation for this failure in solving major environmental problems can be the lack of radical or challenging pictures of future solutions and broadly anchored strategies for how to reach them. In addition, a multi-actor approach including, e.g., industry, governments, academia, and individuals is often missing. This article mainly focuses on the role of industry in being a key actor in sustainability transformations. Industry is responsible for a large share of society's material and energy flows and provides products and services that not only are causing the above mentioned problems but also can provide solutions to the same. Irrespective of this, it is argued that many solutions cannot be achieved without the close incorporation of industry and business dimensions (Loorbach and Wijsman, 2013), while not neglecting the necessity of other actors.

Several tools and approaches have been developed and applied to facilitate future-oriented studies, the shaping of sustainability scenarios (for an overview, see Börjesson et al., 2006, and Höjer et al., 2006), and the formulation of business strategies to reach a more sustainable future (e.g. Robért et al., 2002). Choosing which tool to use depends on the purpose in working with or trying to understand the future. These can be simple forecasts to make different types of prognoses, assessments of how to handle risks due to changing circumstances (e.g. "what if" scenarios), or ways to reach a desired future (e.g. back-casting). One thing many of these tools have in common is the necessity of describing or picturing the future. In relation to sustainable development, this can be problematic since a sustainable future can hardly be defined in detail. This calls for the necessity of expanding the toolbox for future-oriented studies with approaches that can handle strategy and goal formulation, while acknowledging an undetermined future. Such approaches should also stimulate new thinking (outside the box) and be able to handle the idea that the final goal might not be known at the beginning.

One interesting approach used by knowledge-intensive companies during the 2000s in Sweden was called "Jam Sessions." This was used to manage knowledge, knowledge creation, and knowledge communication in the FENIX program, an action research program involving academia and several large knowledge-based firms in Scandinavia (Börjesson and Fredberg, 2004). Experiences from using Jam Sessions in the FENIX program were, e.g., that it opened up an arena for discussing matters outside everyday routines and that it helped create a language for as yet unformulated issues of high importance for strategic planning 
and building trust between the participants (Börjesson and Fredberg, 2004). These experiences make it interesting to test whether the same or a similar approach could be applied in the field of sustainability to help overcome some of the deficiencies of more commonly used methods and approaches. Whereas the challenges for the participants in the FENIX program to a large extent were related to fast developments in e.g. the IT or biotech sectors, Sustainability Jam Sessions (which are described in this article) combine the general sustainability challenge with management and business development challenges. Thus, it can relate to any actor interested in transforming its activities towards sustainability.

Scientific conferences provide creative meeting places where researchers can present early research findings and exchange ideas. Conferences addressing sustainability also often have the ambition of interacting with society and transferring ideas and experiences between researchers and practitioners. During the preparations for the $18^{\text {th }}$ conference of the Greening of Industry Network (GIN2012), the idea was launched to combine a traditional conference structure with more outspoken information and knowledge sharing between stakeholders in the hosting region of East Sweden and the conference participants. For that purpose, the approach of Sustainability Jams Sessions was developed and applied with the intention of enriching both future research activities and business and regional development.

The aim of this article is twofold. First it aims to introduce the concept of Sustainability Jam Sessions (SJS's). Second it aims to describe how SJS's were applied at the GIN2012 conference and present the achieved outcomes.

This is done by first describing how Jam Sessions have been used in other areas, followed by reporting how the concept of SJS was applied at the GIN2012 conference and discussing the learning outcomes and experiences. Finally, conclusions regarding the general usability and characteristics of SJS's are presented.

\section{Jam Sessions}

Jam session as a term for music improvisation is well known. However, the special group interaction associated with jam sessions has been studied and characterized from a more general point of view and has inspired the design of creative workshops within management research programs. In the sections below we will briefly discuss the concept of jam sessions from these perspectives. We start by discussing the general characteristics of the concept as such followed by a section discussing the prerequisites for setting up and organizing jam sessions. In the last section we present experiences from two projects where researchers and companies in cooperation have used jam sessions as a tool for creation of actionable knowledge.

\subsection{The concept Jam Session}

The term "jam session" is primarily associated with music and improvisation. Jamming is often used in jazz, rock, and folk music to come up with new ideas for songs but may also be a live-creation of music in front of an audience. The real time self-organization of the 
musicians is a fascinating process and jazz jam sessions have been studied and characterized by Katz and Longden (1983) as an example of small group processes where the authority shifted between the musicians in a democratic type of authority relations. Musicians in their experiment stated that they enjoyed jamming "because of the sharing of the responsibilities for making music" (Katz and Longden 1983, p 47) and that "the energy and creativity of the group can exceed that of the individuals" (ibid, p 47). Jams were also described as an example of a collaborative type of peer relation that strives to reduce tension with an overall aim towards a common goal and where the degree of intimacy between the participants is of lesser interest while, as a musician in the experiment puts it, the "common objective is to play with sympathy to the other guy" (ibid, p 48).

The unique type of relationship or state of mind that is the basis for a jam session has been further characterized by Eisenberg (1990), who advocates jamming as a desirable way to balance autonomy and interdependence. As an option between a nondisclosive and an intimate disclosive relation, jamming is described as a close, nondisclosive relation based on collective action:

\begin{abstract}
Jamming stresses coordination of action over the alignment of cognitions, mutual respect over agreement, trust over empathy, diversity over homogeneity, loose over tight coupling, and strategic communication over unrestricted candor. (Eisenberg, 1990, p 160)
\end{abstract}

Eisenberg further states that jamming meets the demands of effective organization:

An overemphasis on intention and personality can paralyze action; excessive openness can jeopardize community; and overly strong cultures can stifle autonomy and impede adaptability. A different view of communicating and organizing is needed; one that considers both sides of the dialectic together and consequently does not privilege openness and consensus over selective disclosure and coordinated action. (ibid, p 145)

With jamming being seen as a model for effective organization, it is not surprising to find that jam sessions have been used as a tool in action and management research for business development. In the above mentioned FENIX Research Program, an action research collaboration between two Swedish universities and several large knowledge-based firms, jam sessions were the central activity of what was called the table tennis research process (Adler and Shani, 2001), an intensely interactive action research process between academia and industry. Here, jam sessions are described as "boundary-spanning workshops where the actual research takes place. Data is collected, analyzed, and interpreted, conclusions are drawn, ideas for action tested, and redefinition of research issues occurs" (Adler and Shani, 2001, p 52). In the workshops, the researchers gathered different types of actors representing different perspectives that were normally not considered at the same time. The variety of perspectives made it possible for the researchers to push back provocations and intermediate theories to the practitioners. These theories were tested in day-to-day activities and served as a basis for 
an ongoing development process. As described by Börjesson and Fredberg (2004, p 139): "In essence, a jam session is a method for trying to formulate what has remained unformulated. This is achieved by changing perspectives on the issues that are subject to discussion."

The jam sessions in the research program aimed to bring new ideas and perspectives on dayto-day activities by letting the jams represent a legitimate arena for out-of-the-box thinking. For the researchers in the program, the jams also gave opportunities to learn how the practitioners discussed and dealt with organizational matters and were described as laboratories for testing organizational practices that can be turned into actionable as well as academic knowledge (Styhre and Sundgren, 2005).

\subsection{How to organize a jam}

The task of organizing for creativity may seem to be contradictory. Yet there is a consensus in the literature on jam sessions, regardless of the field addressed, that there needs to be a common platform of conditions, rules, agreements, and commitment for jamming to take place. Eisenberg summarizes this in the four conditions: Skill, Structure, Setting, and Surrender (Eisenberg 1990). The Skill aspect addresses the fact that all individuals in a jam session should have a theoretical or practical competence or a perspective of importance for the focus of the jam and skills enough to contribute to the discussion for a positive group dynamic. The Structure aspect relates to the importance of basic agreements: frames and rules that are taken for granted for the group to be able to direct its creativity towards the challenge of the actual jam. A clear structure contributes to a feeling of security that deliberates the participants' creativity and risk taking, if not taken too far; too much focus on the rules may limit the creativity of the group. Börjesson and Fredberg (2004) also stress the importance of a clear aim and a well-balanced agenda for the jams not to end up being "nothing more than a nice chat" (ibid, p140). The Setting element deals with the fact that we are more likely to "think outside the box" if we are separated from our daily environment. Even the relations between the participants may be altered from normal patterns to be more based on the practical solving of the challenge of the jam. If such a team formation process is created and trust between the participants is established, Eisenberg's forth condition, Surrender of control, may be met, which in turn allows for for a highly creative atmosphere in the group and positive experiences of flow or transcendence.

In addition to Eisenberg's criteria, Adler and Shani (2001) stress the importance for the topics of the jams to be "red and hot," which in the FENIX program meant being strategically important enough to the company and academically relevant to the researchers involved. Generalizing this, the issue addressed in the jam session should be important enough for the participants to feel a significant commitment and for decision makers and others of relevance for the issue addressed to take part in the experimentation, thereby giving the jam session a practical meaning in the development of the organization. 


\subsection{Experiences from working with jam sessions in two cases}

Börjesson and Fredberg (2004) describe how jam sessions were used in the project "Strategizing in the Digital Media sector" in the FENIX research program. The project had the overall objective of creating new knowledge and better understanding existing knowledge in collaboration between researchers and practitioners from three companies. The challenge for the companies was to find ways to act in the rapid development of the emerging digital media sector around the turn of the millennium. Jam sessions were used in the research program to identify relevant research areas, to communicate results within and across organizational settings, and as a method for collecting data and creating knowledge. For the digital media project, the purposes were to articulate the focus of the research, to collect data, and to validate the output. Jam sessions is described as a methodology or tool for "thinking freely of the future," where the jam methodology at the same time frees the discussion from current thinking and patterns and, through carefully chosen participants and a well-balanced agenda, makes this freedom structured and safe for the participants.

The participating companies described the main gains of the project to be:

- "The open climate devoted to discussing relevant issues for them,"

- "The language creation and conceptual development in the sessions," and

- "The opportunity to get away from the daily routines and to view issues from a different perspective in a new setting" (Börjesson and Fredberg, 2004, p 137).

Pitfalls identified were:

- "Not finding the right balance for the agenda,"

- "Having the wrong people participating," and

- " "Losing the participants to internal politics" (Börjesson and Fredberg, 2004 p 143-144).

The jam sessions were never questioned by the companies but were rather seen as prerequisites for the collaboration.

Adler and Shani (2001) describe the experiences from a series of collaboration projects over the course of six years between different parts of the telecom company Ericson $\mathrm{AB}$ and researchers from Chalmers University of Technology and the Stockholm School of Economics. The typical project lasted around one year on clearly defined issues that could develop into broader scopes or create spinoffs to other related issues. This long-term, boundary-spanning and iterative collaboration used jam sessions as a fundamental engine or laboratory for creating intermediate theories that at the same time served as local theories for action addressing practical issues of high relevance to the company and understanding global phenomena. The research methodology was labeled table tennis research, due to the dynamic and iterative collaboration with short feedback loops between practitioners and researchers. In opposition to the setting criteria described by Eisenberg (1990), the project 
was carried out in the natural work setting and had an overall aim of building a mutual learning system within the firm.

The single most important variable in the process, Adler and Shani (2001) claim, was the identification of a clear research focus. The process was not only crucial for finding the "red and hot" topics through a structured dialogue between practitioners and researchers, but also for building trust among the participating members of the project. The level of trust established had a profound impact on openness, willingness to take risks, involvement, and readiness for mutual learning in the project.

\section{Setting up Sustainability Jam Sessions at GIN2012}

The GIN2012 conference was arranged in the region of East Sweden and had the themes Sustainable Industry, Triple Helix (co-evolutionary rethinking for sustainable regions), and Renewable resources, energy, and bio-fuels. The region of East Sweden was chosen to host the conference partly because of the presence of a number of companies in the absolute forefront in addressing sustainability challenges related to the conference themes. This, in turn, meant that, for these companies, the next steps towards further improvements were complex.

Already at the initial meetings between the GIN board and the local organizers of GIN2012, it was discussed how the conference could contribute in a positive way to development in the host region. It was concluded that conference delegates in general travel to the venue, take part in academic sessions and technical visits, and then go back home. But no real interaction takes place. So the local organizers started to develop ideas about how such interaction and positive contributions could be achieved. The idea of the organizers was to make use of the conference participants' competencies to help the companies come up with ideas about how to tackle sustainability challenges identified by the companies and the organizers in dialogue. Here, the local organizers used a reference group formed with the purpose of supporting the preparations and carrying through the conference. The reference group was led by the region's governor and consisted of companies, authorities, support organizations, and academia from the region.

For some time, the local organizers had developed the idea behind SJS's, and saw the possibility of testing such an approach at the conference. To be able to do so, the format of SJS's had to be aligned to the constraints of a research conference. Important parameters to consider were the limited amount of time, logistics, and a vague idea of who would actually attend the conference and in what numbers.

Second, hosts willing to display their challenges and problems had to be identified. The reference group here served as a forum to find a suitable host for the SJS's. From an initial list of more than 15 original ideas, a final list of six hosts was selected based on a combination of potential challenges to be elaborated and the expected number of participants. 
A general template of an SJS was developed, stating that each SJS must have a predefined challenge to be solved. The challenges had to be at the same time relevant for the hosting company/companies and related to the general themes of the GIN conference. Each SJS was assigned a moderator from the local organizers and a host from the participating companies. A template for a time plan was developed, including activities such as technical visits, presentations, and problem-solving workshops. It was also seen as necessary to document the SJS's so that the outcomes could be reported back to the conference and used for future work. Using the template, the local organizers visited the hosts and, in a series of prepreparation meetings, defined and refined the challenges and made a detailed plan of activities for each SJS individually.

Short descriptions of the SJS's were posted on the conference's homepage and, in several cases, links to more detailed presentations of the hosts were posted as well. When registering for the conference, the participants were asked to indicate their preferences for different SJS's. A "Practitioners' offer" was offered to regional actors interested in taking part in the SJS's but not in the full conference. A special offer was also prepared for students to take part in the SJS's to broaden the background of the participants. Based on the registrations to the conference, a list of participants was created for each SJS.

On the day of the SJS's (the second day of the conference), buses collected the participants at the conference venue and transported them to the hosts for the SJS's. All SJS's were performed between lunch and the conference dinner on the same day. On the third and final day of the conference, the completed SJS's were reported and a general discussion was held in plenum about the outcomes.

The number of participants in the SJS's varied from 20 to 33. In addition to hosts and academia from the conference, all jam sessions had representatives from other companies and regional business support organisations. All but one (Holmen AB) also involved students from Linköping University. A broad spectrum of participants' backgrounds was sought for to create a multitude of perspectives on the challenges.

The main challenges addressed are shown in Table 1. Three overarching themes can be identified: new sustainable business opportunities, further development of low-emitting industry, and increased material utilization and reuse. 
Table 1. Summary of Sustainability Jam Sessions at the $18^{\text {th }}$ Greening of Industry Network conference.

\begin{tabular}{|c|c|c|c|}
\hline Host & Main challenge(s) & Direct outcomes & Indirect outcomes \\
\hline $\begin{array}{l}\text { Tekniska Verken AB (TV), } \\
\text { utility company in the city } \\
\text { of Linköping }\end{array}$ & $\begin{array}{l}\text { How do we establish a waste } \\
\text { management system that } \\
\text { maximizes the amount of raw } \\
\text { materials for high-quality } \\
\text { reuse and material recycling? } \\
\text { Is it possible to make } \\
\text { recycling activities } \\
\text { entertaining and, if so, then } \\
\text { how? }\end{array}$ & $\begin{array}{l}\text { Ideas and suggestions on how to make waste sorting easier } \\
\text { and more entertaining. This included technical solutions and } \\
\text { mass-education and motivational events such as } \\
\text { educational Saturday cartoons, junk festivals, entertainment } \\
\text { at recycling centers, attractive waste vehicles, and garbage } \\
\text { lotteries. }\end{array}$ & $\begin{array}{l}\text { A GIN participant invited TV } \\
\text { and Linköping University (LiU) } \\
\text { to join an EU-proposal that was } \\
\text { already prepared with } 4 \text { other } \\
\text { European partners. TV and LiU } \\
\text { joined the consortium, but the } \\
\text { proposal was not funded. }\end{array}$ \\
\hline $\begin{array}{l}\text { Toyota Material Handling } \\
\text { Europe } A B \text {, fork lift } \\
\text { producer }\end{array}$ & $\begin{array}{l}\text { How do we make zero } \\
\text { emission production also the } \\
\text { most profitable? How can the } \\
\text { Toyota paint shop reduce its } \\
\text { environmental impact from } \\
\text { an already high eco-efficiency } \\
\text { level through optimization } \\
\text { and out-of-the-box thinking? } \\
\text { Can some of the conclusions } \\
\text { be generalized? }\end{array}$ & $\begin{array}{l}\text { Suggestions for further improvements and general aspects } \\
\text { on zero emission production. Tentative improvements were } \\
\text { e.g. the use of internal excess heat, further reduced waste } \\
\text { generation, and questioning the necessity of painting. } \\
\text { General learning outcomes were related to the set-up of the } \\
\text { project for the development of the paint shop. Of special } \\
\text { interest was the broad collaboration of actors and in } \\
\text { particular the involvement of the municipality. }\end{array}$ & $\begin{array}{l}\text { In } 2014 \text { a cooperation } \\
\text { agreement was signed } \\
\text { between Toyota and LiU in the } \\
\text { area of lifecycle based offerings } \\
\text { including life cycle costing. }\end{array}$ \\
\hline $\begin{array}{l}\text { Agricultural cluster } \\
\text { initiative Vreta Kluster and } \\
\text { four small companies: } \\
\text { Biototal AB, Energifabriken } \\
\text { AB, Gothia Redskap AB, } \\
\text { and Svejo dairy farm }\end{array}$ & $\begin{array}{l}\text { How can "fossil free farming" } \\
\text { companies increase their } \\
\text { market share? }\end{array}$ & $\begin{array}{l}\text { SWOT-analyses which were valuable to the participating } \\
\text { companies. Common strengths identified were the } \\
\text { companies' sustainability performance and high customer } \\
\text { value. Weaknesses were dependence on existing } \\
\text { infrastructure and systems and pedagogical challenges in } \\
\text { relation to customers. Opportunities included changing } \\
\text { price relations that will make their products more } \\
\text { competitive. A threat was the challenge of getting paid for } \\
\text { environmental services provided. }\end{array}$ & $\begin{array}{l}\text { Further broadening of the } \\
\text { concept of fossil free farming } \\
\text { to include climate performance } \\
\text { assessments of practices from } \\
\text { the other companies. } \\
\text { Collaboration with the } \\
\text { university researchers has } \\
\text { deepened since the session as } \\
\text { well as cooperation between } \\
\text { participating companies. }\end{array}$ \\
\hline SAAB AB, defense and & How can ICT skills be used to & Identification of many needs of ICT for more efficiency such & New cooperation among \\
\hline
\end{tabular}




\begin{tabular}{|c|c|c|c|}
\hline $\begin{array}{l}\text { security company; further } \\
\text { participation of Tekniska } \\
\text { Verken } A B \text { and the young } \\
\text { ICT (information and } \\
\text { communication } \\
\text { technology) companies } \\
\text { Twingly and Headler }\end{array}$ & $\begin{array}{l}\text { improve environmental } \\
\text { sustainability? }\end{array}$ & $\begin{array}{l}\text { as peak cut/decrease of electricity consumption, health } \\
\text { care, replacing travel, and improving city life that are or } \\
\text { could be turned in to commercial services. The need of a } \\
\text { more open co-operation among government, industry, and } \\
\text { academia was highlighted. }\end{array}$ & participants. \\
\hline $\begin{array}{l}\text { Holmen AB and its } \\
\text { Braviken combine } \\
\text { consisting of a Pulp and } \\
\text { Paper mill and a Saw mill; } \\
\text { Holmen Biorefinery } \\
\text { Development Center }\end{array}$ & $\begin{array}{l}\text { How can Holmen best utilize } \\
\text { the residual products from } \\
\text { the Braviken combine in } \\
\text { order to create sustainable } \\
\text { products? } \\
\text { What kind of mechanisms } \\
\text { need to be in place to make } \\
\text { companies like Holmen dare } \\
\text { to invest in new technology? }\end{array}$ & $\begin{array}{l}\text { Identification of three areas of development: } \\
\text { Internal quality improvements } \\
\text { Finding more valuable products out of lignin/cellulose etc. } \\
\quad \text { - From wood in general } \\
\text { - From rest products } \\
\text { Opening up to entrepreneurs/innovators/researchers and } \\
\text { the start of Holmen Sustainable Business Incubator. }\end{array}$ & $\begin{array}{l}\text { Sustainable Business } \\
\text { Accelerator developed } \\
\text { together with three SMEs and } \\
\text { four large companies to } \\
\text { capture new business ideas } \\
\text { originating from large } \\
\text { companies' activities. }\end{array}$ \\
\hline $\begin{array}{l}\text { The Händelö Cluster in } \\
\text { Norrköping: Represented } \\
\text { by the energy company } \\
\text { E.ON, bioethanol producer } \\
\text { Agroetanol AB, and } \\
\text { recycling industry Econova } \\
\text { AB }\end{array}$ & $\begin{array}{l}\text { What can we learn from the } \\
\text { Händelö area for } \\
\text { dissemination? } \\
\text { Is Industrial Symbiosis } \\
\text { transforming industry? } \\
\text { Has the business model been } \\
\text { changed by Industrial } \\
\text { Symbiosis? } \\
\text { How can we strengthen the } \\
\text { issue of sustainability in } \\
\text { Industrial Symbiosis? }\end{array}$ & $\begin{array}{l}\text { It was concluded that traditional business links are the basis } \\
\text { for doing business in an industrial symbiosis setting. In turn, } \\
\text { driving symbiotic relationships between actors creates a } \\
\text { basis for certainty in financial stability. Finally, trust was } \\
\text { seen as necessary for further exploring industrial symbiosis } \\
\text { links. }\end{array}$ & \\
\hline
\end{tabular}


All but one ${ }^{1}$ SJS started with general company information about the hosts and a technical visit to give the attendants a general picture of the current activities of the hosts. Thereafter, an introduction of the challenge to be addressed was made. This was done slightly differently in the various SJS's. At SAAB AB, three inspirational presentations were done by invited companies and at Vreta Kluster, four SME (small and medium-sized companies) presented their businesses and the environmental benefits of their customer offerings. At Händelö Cluster, three companies involved in the symbiotic network described their activities. At all venues, parallel workshops were performed trying to solve the challenges presented. At the end, all subgroups joined for summarizing and formulating joint conclusions. At the Tekniska verken $\mathrm{AB}$, a jury was used to identify the most promising solution presented by the workshop groups.

\section{Results from the Sustainability Jam Sessions at GIN2012}

Given that each SJS worked with its own main challenges and had a different setup, the outcomes varied. In general, the results from the jam sessions can be classified as direct and indirect outcomes (spinoffs). Among the direct outcomes, several SJS's came up with suggestions for internal quality improvements. Furthermore, they resulted in new or improved business ideas for the participating companies. Indirect outcomes were new cooperations between academia and practitioners as well as between different practitioners. Of particular interest was the suggestion of a Sustainable Business Incubator launched at the Holmen jam session. That idea has now been further elaborated to become a Sustainable Business Accelerator to be launched during 2014. The idea behind the accelerator is open innovation around the current activities of four large companies (of which three were hosts of SJS's at GIN 2012) and the innovating capacity of SMEs. SMEs will be invited to come up with new business ideas that will be qualified and evaluated by the accelerator before the SME and large company jointly perform a pre-study with the aim of finding new sustainable business solutions to solve environmental problems. The initial theme will be upgrading of waste products. Further, in 2014 cooperation agreement was signed between Toyota and Linköping in the area of lifecycle based offerings including life cycle costing. The trust built between the organizations while preparing and doing the SJS was judged as important in creating this agreement.

It should be noted that all SJS's could be carried out as planned. Even though no formal evaluation was done, the general impression from the participants was that this was something new, innovative, and inspiring. In the documentation of the SJS's, we also noted drawbacks with the chosen approach. Of special interest is that the format itself could have limited the output from the jam sessions. Time constraints caused by the conference format was mentioned as a drawback and more time would have most likely resulted in other or additional outcomes. The limited amount of time also led to the challenges having to be narrowed down, which in some cases led to the participants feeling a bit locked in and not

${ }^{1} \mathrm{SAAB} A B$ could not welcome visitors to their premises due to security reasons. 
allowed to think as broadly as possible. Finally, the lack of information about other participants' skills and experiences was indicated as hindering the discussions. In conclusion, these constraints most likely can be tracked to the inclusion of the SJS's in a conference and not performed as a single event.

On the other hand, using the GIN conference as a platform most likely increased the diversity of the participants (both geographically and by experience). Attracting highly qualified participants from a large number of countries just for regional jam sessions would be very difficult. This diversity is also one of the strengths of the SJS and relates to the important condition of Skill mentioned by Eisenberg (1990). Further elaborating on the four conditions of successful jams (Skill, Structure, Setting, and Surrender; ibid) Structure was dealt with by the detailed planning of the SJS's and the outspoken role of the moderators and hosts. The technical visits and leaving the conference venue further aimed to break the normal patterns of a conference and create the right Setting for the jam sessions. Finally, the technical visits and inspirational talks by invited speakers and host aimed to generate an open atmosphere to facilitate the Surrender of control.

\section{Analysis and discussion}

The transformation of society towards sustainability may be the most profound global challenge of the industrialized era. Though developments e.g. in ICT, material science, or biotechnology have a major impact on society, sustainability issues challenge the very root of societal agreements, habits, and economic systems. Companies and organizations may already have a hard time tackling rapid technical and sociological developments; meeting the sustainability challenge increases complexity and uncertainty to another level.

Predictions of the future and scenario planning are powerful tools to help companies with ambitions to address sustainability and navigate and make strategic plans in a proactive way. Still, the high uncertainty and the political dimension of the transformation towards sustainability make any agenda that is too long term risky. It is also obvious that a societal transformation of this magnitude calls for increased cooperation between actors to reformulate basic conditions and agreements, developing business models and relations that reward sustainability. The need for means and methods for such reformulation and development processes is closely related to the creation of new actionable knowledge (Adler and Shani, 2001) and the establishment of arenas for creative cooperation between stakeholders. Knowledge creation, furthermore, is closely related to formulation of the silent knowledge of practitioners (tactic knowledge) or to the combination of experiences from different areas of expertise. Whereas it is mainly practitioners that possess this tactic knowledge, companies or organizations rarely have the means or structures for systematic knowledge creation (Adler and Shani, 2001). Here, academia may have a role to, in cooperation with practitioners, set the stage and serve as guides or provokers in changing perspective on everyday experiences or in helping in the formulation of tactic knowledge. To 
make room for the formulation of such new knowledge, it is often necessary to establish an arena outside the daily routine.

Our experience from GIN2012 is that jam sessions can serve as such an arena. This is in line with the learning from the jam sessions of the FENIX project (Börjesson and Fredberg, 2004), as well as with Eisenberg's emphasis on the creation of a structure outside daily routines where risk is rewarded, not punished, in creating a positive environment for the development and survival of novel ideas (Eisenberg 1990). Also in accordance with Eisenberg is the emphasis on a careful selection of participants to ensure equal skill levels in relation to the theme of the jam session for jamming to occur. Here, a prerequisite for the design of the SJS's at GIN2012 was that they should include both deep knowledge of the actual branch or business and knowledge of the related sustainability challenges.

At the GIN2012 conference, the SJS's were affected by a number of special conditions: the short time for the jams and the groups being made up of people meeting just for this one occasion. Furthermore, all but one SJS (Tekniska Verken) were arranged more or less for its own sake, although the topics were of vital interest to the hosts. At Tekniska verken the SJS was part of an ongoing process with other similar exercises involving a high school student innovation camp.

Despite much time being spent on formulating the challenges, designing the layout of the jams, and finding the best introductions and inspirational presentations, the participants had to pass a number of stages in a fairly short time to reach to a more focused discussion of the challenge of the jam; there had to be some mapping of prerequisites, some brainstorming of ideas, and then, eventually, a more focused jamming on the actual topic.

The six SJS's at GIN2012 all had elements of mapping and brainstorming, but in some of them the elements of jamming were weaker. This could partly be explained by the topics being too complex or too vague for the actual combination of skills and the time allotted. In these cases, an inventory of prerequisites and initial idea generation was still a good result.

All SJS's that came closest to actually jamming were addressing questions related to core business challenges for the hosting partner or, to use the Adler and Shani (2001) concept, challenges that were "red and hot" issues for the hosts. This, in turn, led to better focus, stronger commitment, and a safer setting as the challenges were well known to the hosts. It should also be mentioned that these SJS's suffered as a result of the short time allotted for the exercise, as intense and creative discussions had to be finished far too early according to several of the participants.

These results indicate that preparations of jam sessions have to be taken to the point where "red and hot" topics are readily apparent. One possible recommendation would be to have mapping and brainstorming sessions to prepare for the SJS's rather than spending too much time passing through these stages in the actual jamming situation. 


\section{Conclusions and recommendations}

Based on the experiences from the GIN2012 conference, we conclude that Sustainability Jam Sessions can be a useful tool for creating arenas where expertise from e.g. certain branches of industry can interact with sustainability professionals and researchers to address sustainability challenges. Key factors for successful SJS's are mainly the same as for jam sessions generally. These success factors are skill, structure, setting, and surrender of control. Still, the single most important factor according to the experiences from the GIN2012 SJS's is finding "red and hot" topics for the jams; the closer to core business challenges the jam topics came the more focused the discussions got. Finding "red and hot" topics will also help finding the right actors and skilled individuals for the challenges to be addressed.

The pre-preparation of the jams is therefore of vital importance. When "red and hot" topics are hard to define one recommendation would be to have mapping and brainstorming sessions to prepare for the SJS's rather than spending too much time passing through these stages in the actual jamming situation.

It is recommended that other research conferences in the sustainability area use SJS's if the intention is to boost the interaction between the conference and the host region or nonacademic organizations in general. By doing so, good relations between actors in a region can be created, constituting a platform for future regional and business development activities. However, the special prerequisites related to using SJSs at a conference, e.g. its' being a single occasion event made up of people not knowing each other, calls for special arrangements to prepare for and make use of the full potential of the group interaction. In the evaluation of the SJSs at GIN2012 participants suggested the creation of open forums on the internet where information could be found and discussions be directed prior to and after the conference.

We also suggest that a similar approach can be used in regional development without a visiting international research conference for creating an infrastructure for learning and transformation towards sustainability or for initiatives for open innovation.

\section{References}

Adler, N. and Shani R., 2001. In Search of an Alternative Framework for the Creation of Actionable Knowledge: Table-Tennis Research at Ericsson. Research in Organizational Change and Development, 13, $43-79$.

Börjeson, L., Höjer, M., Dreborg, K.-H., Ekvall, T. and Finnveden, G .2006. Scenario types and techniques: Towards a user's guide. Futures, 38, 723-739.

Börjesson, S. and Fredberg, T., 2004. Jam Sessions for Collaborative Management Research, in: Adler, N. et al (Eds), Collaborative Research in Organizations, Sage Publications, Inc., Thousand Oaks, California, p 135-148. 
Eisenberg, E.M., 1990. Jamming: Transcendence Through Organizing. Communication Research, 17, 139-164

Katz, P. and Longden, S., 1983. The Jam Session. Social Work With Groups, 6:1, 37-52.

Loorbach, D. and Wijsman, K., 2013. Business transition management: exploring a new role for business in sustainability transitions. Journal of Cleaner Production, 45, 20-28.

Rockström, J., Steffen, W., Noone, K., Persson, Å., Chapin, III, F.S., Lambin, E., Lenton, T.M., Scheffer, M., Folke, C., Schellnhuber, H., Nykvist, B., De Wit, C.A., Hughes, T., van der Leeuw, S., Rodhe, H., Sörlin, S., Snyder, P.K., Costanza, R., Svedin, U., Falkenmark, M., Karlberg, L., Corell, R.W., Fabry, V.J., Hansen, J., Walker, B.H., Liverman, D., Richardson, K., Crutzen, C. and Foley. J. 2009. A safe operating space for humanity. Nature, 461, 472-475.

Styhre, A. and Sundgren, M., 2005. Action Research as Experimentation. Systematic Practice and Action Research, 18:1, 53-65.

Höjer, M. Ahlroth, S. Dreborg, K-H.; Ekvall, T. Finnveden, G. Hjelm, O. Hochschorner, E. Nilsson, M. and Palm, V. 2008. Scenarios in environmental systems analysis tool. Journal of Cleaner Production 16:1958-1970.

Robert K.-H., Schmidt-Bleek B., Aloisi De Larderel J., Basile G., Jansen J.L., Kuehr R., Price Thomas P., Suzuki M., Hawken P., Wackernagel M., 2002. Strategic sustainable development - Selection, design and synergies of applied tools. Journal of Cleaner Production10:3, 197-214. 